\title{
LITERATUS \\ research and development thinking paradigm \\ The Increasing Naturalist Intelligence by Planting Methods in TK B Group at KB TK Asaloka on West Jakarta Academic Year 2018/2019
}

Literatus is a journal published by PT Traindo Bangun Negeri, issued two times in one year. Literatus is a scientific publication media in the form of conceptual paper and field research related to general thinking paradigm. It is hoped that Literatus can become a media for academics and researchers to publish their scientific work and become a reference source for the development of science and knowledge.

Our focus:

Social and Culture

Our Scope:

Humanities,

Education,

Management,

History,

Economics,

Linguistics,

Literature,

Religion,

Politics,

Sociology,

Anthropology,

and others.

\author{
Upaya Meningkatkan Kecerdasan Naturalis melalui Metode Bercocok Tanam \\ pada Kelompok TK B di KB TK Asaloka Jakarta Barat \\ Tahun Ajaran 2018/2019
}

\author{
Dini Ameliawati \\ Sekolah Tinggi Keguruan dan Ilmu Pendidikan Panca Sakti \\ Jalan Raya Hankam No.54, RT.005/RW.002, Jatirahayu, Pondok Gede, Kota Bks, Jawa Barat
} 17414

\begin{abstract}
The purpose in this research was to determine the process of implementing the planting method in an effort to improve naturalist intelligence for children. The method used in this study is a class action research method which consists of four steps, there are: planning, implementation, observation, and reflection. This research was conducted on 17 students at KB TK Asaloka on West Jakarta, from April to May 2019. The data collection techniques in this study were observation, field notes, interviews, and documentation. The results of the action in each cycle of class action research obtained an increase in children's naturalist intelligence from the start of the pre-cycle action with the acquisition of an average value are 1.3, or $32 \%$ if on percentage value. Cycle 1 get the acquisition of an average value 2.6, or $62 \%$ if on percentage value. Then, cycle 2 with the acquisition of an average value are 3.7, or equal to $92 \%$ on percentage value. The conclusion of this study is that planting methods are effective in increasing children's naturalist intelligence.
\end{abstract}

Keywords: naturalist intelligence, planting methods

\section{PENDAHULUAN}

Kecintaan anak terhadap lingkungan harus dipupuk sejak dini, yaitu sejak anak mulai mengenal lingkungannya. Kecintaan terhadap tumbuhan, hewan, dan unsur-unsur lain di alam ini perlu dirangsang agar anak mampu memperlakukan alam dengan baik kelak di kemudian hari. Kecintaan anak terhadap alam inilah yang dikenal dengan kecerdasan naturalis.

Kecerdasan naturalis dapat dirangsang dengan berbagai cara, misalnya dari pengenalan sains secara verbal, penyediaan buku-buku sains penuh gambar, kegiatan bercocok tanam, menyiram bunga, memelihara ikan di akuarium, memelihara unggas, mengoleksi mainan replika binatang, mengoleksi benda alam di sekitar anak, hingga pencermatan gejala alam. Perangsangan yang bervariasi memiliki efek dan pengaruh yang lebih kuat karena prinsip belajar anak terpenuhi dari berbagai faktor.

Salah satu kegiatan pengembangan kecerdasan naturalis ialah dengan kegiatan bercocok tanam. Kegiatan bercocok tanam merupakan kegiatan menanam benih-benih tanaman yag diinginkan. Kegiatan ini bertujuan untuk meningkatkan pemahaman anak terhadap proses pertumbuhan tanaman dari mulai menanam hingga memanen hasil tanaman.

Berdasarkan pengamatan yang terjadi di lapangan, khususnya di kelas TK B di KB TK Asaloka. Kemampuan kecerdasan naturalis anak masih rendah. Terlihat dari sebagian besar anak masih menunjukkan kurang perhatian dengan lingkungan sekitarnya. Terlihat dari jumlah siswa 17 anak, yang terdiri dari delapan laki-laki dan sembilan perempuan, ada sepuluh anak yang masih membuang sampah sembarangan, memetik tumbuhan sembarangan, dan tidak 
merawat tanaman. Dengan perilaku tersebut dapat dikatakan bahwa siswa KB TK Asaloka, khususnya kelompok B, perlu mendapatkan stimulus untuk dapat meningkatkan kecintaannya terhadap lingkungan sekitar mereka. Sementara itu, kinerja guru pada proses pembelajaran pengembangan kecerdasan naturalis masih rendah, terlihat dari metode pembelajaran yang masih monoton dan kurang bervariasi.

Berdasarkan permasalahan yang telah diuraikan di atas, peneliti tertarik untuk meneliti Upaya Meningkatkan Kecerdasan Naturalis melalui Metode Bercocok Tanam pada kelompok TK B di KB TK Asaloka.

Vol. 1, No. 1,

October 2019,

pp. 31-36

e-ISSN:

2686-5009

\section{Kecerdasan Naturalis}

Menurut Armstrong (2009) kecerdasan naturalis merupakan keahlian dalam mengenali dan mengklasifikasikan berbagai spesies flora dan fauna, dari sebuah lingkungan individu. Hal ini juga mencangkup kepekaan terhadap fenomena alam lainnya (misalnya formasi awan, gunung, dan lainnya) dan dalam kasus tumbuh di lingkungan perkotaan, kemampuan untuk membedakan benda-benda mati seperti mobil, sepatu, dan sampul CD (compact disc) Menurut Suyadi (2009) kecerdasan naturalis sangat dibutuhkan setiap orang sejak mereka usia dini. Sebab kecerdasan ini mampu menjaga dan memelihara "nalurinya" untuk hidup di alam bebas bersama dengan makhluk-makhluk ciptaan Tuhan yang lain.

Menurut Muhammad Yaumi (2013) kecerdasan naturalis sebagai keahlian mengenali dan mengategorikan spesies, baik flora maupun fauna di lingkugan sekitar dan kemampuannya dalam mengolah dan memanfaatkan alam serta melestarikan alam.

.Berdasarkan pendapat para ahli di atas, dapat disimpulkan bahwa kecerdasan naturalis adalah kemampuan anak dalam mengenali, mengklasifikasikan, dan memelihara flora serta lingkungan yang ada disekitarnya.

\section{Metode Bercocok Tanam}

Menurut Muspiroh (2014) kegiatan bercocok tanam merupakan kegiatan yang direncanakan dan dilaksanakan oleh siswa bersama guru. Proyek ini bertujuan menumbuhkan kecintaan anak pada tumbuhan sekaligus merangsang cakrawala pengetahuan berkembang biak tumbuhan.MenurutYasbiati, Naturalis, \& Annisa (2017) kegiatan bercocok tanam adalah salah satu kegiatan yang mampu meningkatkan kecerdasan naturalis anak, karena dengan kegiatan ini anak diajak langsung untuk menemui bahan-bahan alam, di antaranya tanah, biji-bijian, pupuk dan air. Anak diajak untuk menanam dengan cara terjun langsung ke alam. Tidak banyak anak yang menyukai kegiatan ini karena mereka berpikir bahwa kegiatan ini kotor dan akan mengotori pakaian mereka.

Dari beberapa pendapat di atas dapat disimpulkan bahwa metode bercocok tanam merupakan suatu metode yang direncanakan dan dilaksanakan oleh siswa bersama guru. Metode ini bertujuan untuk menumbuhkan kecintaan anak pada tumbuhan sekaligus merangsang cakrawala pengetahuan terkait tumbuhan. Metode ini diharapkan mampu meningkatkan kecerdasan naturalis anak, karena dengan kegiatan ini anak diajak langsung untuk menemui alam. Lingkungan alam inilah tempat yang ideal bagi anak-anak untuk dapat menggunakan kreativitasnya.

\section{METODE}

Penelitian ini menggunakan pendekatan penelitian tindakan (classroom action research). bahwa penelitian tindakan kelas merupakansuatu pencermatan terhadap kegiatan belajar berupa sebuah tindakan yang berfokus pada proses belajar mengajar. Tujuannya untuk memperbaiki mutu praktik pembelajaran di kelas. Ada empat proses dalam penelitian tindakan kelas, yaitu: perencanaan (planning), penerapan (action), pengamatan dan evaluasi (observing andevaluation), dan refleksi (reflecting). 


\section{LITERATUS \\ research and development thinking paradigm}

Literatus is a journal published by PT Traindo Bangun Negeri, issued two times in one year. Literatus is a scientific publication media in the form of conceptual paper and field research related to general thinking paradigm. It is hoped that Literatus can become a media for academics and researchers to publish their scientific work and become a reference source for the development of science and knowledge.

Our focus:

Social and Culture

Our Scope:

Humanities,

Education,

Management,

History,

Economics,

Linguistics,

Literature,

Religion,

Politics,

Sociology,

Anthropology,

and others.

Model penelitian tindakan kelas yang akan digunakan dalam penelitian ini adalah model Kemmis dan McTaggart. Model ini dipilih karena model Kemmis dan McTaggart memiliki langkah yang sederhana dan lebih mudah dipahami. Pada model tersebut terdapat empat tahapan di tiap siklusnya. Empat tahapan tersebut ialah perencanaan (planning), pelaksanaan (action), pengamatan (observing), dan refleksi (reflekting).Sesuai dengan karakteristik penelitian tindakan kelas, maka keberhasilan tindakan berubah ke arah perbaikan, baik yang terkait dengan anak ataupun pembelajaran menggunakan metode bercocok tanam dalam meningkatkan kecerdasan naturalis anak usia 5 sampai 6 tahun dibandingkan dengan sebelum ada penerapan metode bercocok tanam dan sesudah diterapkannya metode bercocok tanam.

Pengumpulan data dalam penelitian ini melalui data sekunder. Terdapat empat data sekunder yang digunakan dalam penelitian ini ialah obsevasi, catatan lapangan, wawancara dan dokumentasi. Instrumen yang digunakan sebagai alat pengambil data dalam penelitian ini adalah lembar observasi. Teknik analisis data yang digunakan dalam penelitian ini adalah teknik dengan melakukan beberapa tahapan di antaranya reduksi data, penyajian data dan verifikasi. Teknik analisis data dalam penelitian ini pada dasarnya menggunakan analisis kualitatif, data yang diperoleh dari hasil observasi dan dokumentasi dianalisis ke dalam bentuk deskriptif

\section{HASIL DAN PEMBAHASAN}

\section{Hasil}

Dari penilaian kemampuan awal kecerdasan naturalis anak dapat dianalisis bahwa kemampuan awal siswa kelompok B di KB TK Asaloka pada indikator mampu mengenali nama tumbuhan nilai rata-rata yang di peroleh 1,2 itu ada pada kategori mulai berkembang (MB). Artinya dalam kemampuan mengenali nama tumbuhan rata-rata anak belum mampu. Jika dilihat dari besarnya persentase kemampuan anak dalam mengenali nama tumbuhan hanya sebesar $31 \%$ atau sebagian kecil saja anak yang mampu mengenali nama tumbuhan. Artinya sebagian besar atau $69 \%$ anak masih harus mendapatkan stimulus dan latihan untuk meningkatkan kemampuan mengenali nama tumbuhan.

Pada indikator mampu mengenali jenis-jenis tumbuhan nilai rata-rata yang diperoleh 1,0 itu ada pada kategori belum berkembang (BB). Artinya dalam kemampuan mengenali jenis-jenis tumbuhan rata-rata anak belum mampu. Jika dilihat dari besarnya persentase kemampuan anak dalam mengenali jenis-jenis tumbuhan hanya sebesar $25 \%$ atau hanya sebagian kecil saja anak yang mampu mengenali jenis-jenis tumbuhan. Artinya sebagian besar atau $75 \%$ anak masih harus mendapatkan stimulus dan latihan untuk meningkatkan kemampuan mengenali jenis-jenis tumbuhan.

Pada indikator mampu membedakan jenis-jenis tumbuhan nilai rata-rata yang diperoleh 1,0 itu ada pada kategori belum berkembang (BB). Artinya dalam kemampuan membedakan jenis-jenis tumbuhan rata-rata anak belum mampu. Jika dilihat dari besarnya persentase kemampuan anak dalam membedakan jenis-jenis tumbuhan hanya sebesar $25 \%$ atau hanya sebagian kecil saja anak yang mampu membedakan jenis-jenis tumbuhan. Artinya sebagian besar atau $75 \%$ anak masih membutuhkan stimulus dan latihan dalam meningkatkan kemampuan membedakan jenis-jenis tumbuhan.

Pada indikator mampu membedakan bagian-bagian tumbuhan nilai rata-rata yang di peroleh 1,4 itu ada pada kategori mulai berkembang (MB). Artinya dalam kemampuan membedakan bagian-bagian tanaman rata-rata anak belum mampu. Jika dilihat dari besarnya persentase kemampuan anak dalam membedakan bagian-bagian tumbuhan hanya sebesar 35\% atau sebagian kecil saja anak yang mampu mengenali bagian-bagian tumbuhan. Artinya sebagian besar atau $65 \%$ anak masih harus mendapatkan stimulus dan latihan untuk meningkatkan kemampuan membedakan bagian-bagian tumbuhan.

Pada indikator mampu merawat tumbuhan nilai rata-rata yang di peroleh 1,7 itu ada pada kategori mulai berkembang (MB). Artinya dalam kemampuan merawat tumbuhan rata- 
rata anak belum mampu. Jika dilihat dari besarnya persentase kemampuan anak dalam membedakan bagian-bagian tumbuhan hanya sebesar $43 \%$ atau sebagian anak saja yang mampu merawat tumbuhan. Artinya sebagian besar atau 57\% anak masih harus mendapatkan stimulus dan latihan untuk meningkatkan kemampuan merawat tumbuhan.

\section{Pembahasan}

Berdasarkan tindakan di setiap siklus penelitian tindakan kelas ini memperoleh peningkatan kecerdasan naturalis anak dari mulai tindakan pra siklus dengan perolehan ratarata nilai 1,3. Jika dipersentasekan sebesar 32\%, siklus 1 dengan perolehan rata-rata nilai 2,6. Jika dipersentasekan sebesar $62 \%$, dan siklus 2 dengan perolehan rata-rata nilai 3,7. Jika dipersentasekan sebesar $92 \%$. Hasil analisis menyatakan bahwa dari mulai pra siklus hingga siklus 2 mengalami perubahan dan peningkatan yang signifikan, hal ini dikarena setiap siswa khususnya siswa TK B di KB TK Asaloka Jakarta Barat sangat antusias dengan kegiatan bercocok tanam dan memiliki rasa ingin tau yang besar dalam setiap proses pembelajaran. Sehingga siswa mampu memahami setiap penjelasan dan pembelajaran yang diberikan.

Penggunaan metode bercocok membuat anak terlibat secara langsung dalam proses pembelajaran. Karena anak tidak hanya belajar di sekolah, tapi anak juga diajak langsung untuk mengamati kebun petani untuk melakukan pengamatan terhadap tumbuhan dan lingkungan perkebunan. Selain itu juga anak terlibat aktif dalam proses pembelajaran, karena anak mempunyai pengalaman langsung terhadap setiap materi yang dipelajari, sehingga kecerdasa naturalis anak dapat meningkat. Metode bercocok tanam dalam meningkatkan kecerdasan naturalis anak ini juga sebagi proses pembelajaran yang menyenangkan karena anak dapat mengeksplorasi diri dan anak juga bisa tahu proses dari mulai menanam tumbuhan, merawat tumbuhan hingga memanen hasil.

Pendapat ini sejalan dengan teori yang dikemukakan Yunisari \& Amsal(2016)melalui pembelajaran disentra bahan alam dapat mengembangkan kecerdasan naturalis anak kelompok B2 pada PAUD Terpadu Dharma Wanita. Hal tersebut dapat dilihat dari meningkatnya jumlah presentase kemampuan kecerdasan naturalis anak yang berkembang baik.Respon anak juga mengalami peningkatan yang dilihat pada siklus I masih banyak anak yang belum respon dalam menjawab pertanyaan guru, mengemukakan pendapatnya tentang informasi yang berhubungan dengan tema maupun pada saat praktuk bermain langsung, namun meningkat pada siklus II, anak terlihat mau mengangkat tangan dan memberikan informasi yang diketahuinya tentang sub tema pembelajaran dan $100 \%$ anak melakukan praktek bermain dengan aktif dan sesuai dengan tahapannya dan tujuan pembelajaran.

Peningkatan yang terjadi pada setiap indikatornya menandai bahwa penelitian ini berhasil, karena sudah dapat meningkatkan kecerdasan naturalis pada anak melalui metode bercocok tanam, khususnya pada siswa kelompok B di KB TK Asaloka Jakarta Barat. Dan sudah memenuhi kriteria keberhasilan tindakan, yaitu sebesar 92\% dari seluruh jumlah siswa, mencapai kategori berkembang sesuai harapan (BSH).

\section{PENUTUP}

Hasil analisis data mengenai pelaksanaan penelitian tindakan kelas dalam upaya meningkatkan kecerdasan naturalis melalui metode bercocok tanamn pada kelompok B di KB TK Asaloka Jakarta Barat dapat disimpulkan sebagai berikut:

1. Proses pembelajaran melalui metode bercocok tanam dalam upaya meningkatkan kecerdasan naturalis dilaksanakan dalam rentang waktu 60 menit. Penggunaan metode bercocok tanam yaitu dengan melakukan kegiatan-kegiatan bercocok tanam yang dimana siswa sebagai subyek utama dan mempraktikkan langsung setiap kegiatan pembelajaran dalam bercocok tanam. Upaya meningkatkan kecerdasan naturalis dengan menggunakan metode bercocok tanam ini menjadi strategi untuk penilaian tiga aspek 


\section{LITERATUS \\ research and development thinking paradigm}

Literatus is a journal published by PT Traindo Bangun Negeri, issued two times in one year. Literatus is a scientific publication media in the form of conceptual paper and field research related to general thinking paradigm. It is hoped that Literatus can become a media for academics and researchers to publish their scientific work and become a reference source for the development of science and knowledge.

Our focus:

Social and Culture

Our Scope:

Humanities,

Education,

Management,

History,

Economics,

Linguistics,

Literature,

Religion,

Politics,

Sociology,

Anthropology,

and others.

kecerdasan naturalis yaitu mengenali flora (tumbuhan), mengklasifiasi flora (tumbuhan) dan memelihara flora (tumbuhan). Pada penelitian tindakan kelas ini diharapkan anak mampu mengenali nama tumbuhan, mengenali jenis-jenis tumbuhan, mampu membedakan jenis-jenis tumbuhan, mampu membedakan bagian-bagian tumbuhan dan mampu merawat tumbuhan. Selain itu, diharapkan anak mampu memahami proses menanam hingga memanen tumbuhan, khususnya pada tanaman sayuran. Dan juga diharapkan agar anak mampu membedakan flora (tumbuhan) secara mendetail dari mulai bentuk, warna, aroma dan lain sebagainya. Anak juga diharapkan agar mampu memberitahu atau menceritakan mengenai flora (tumbuhan) dan proses penanaman serta cara merawat atau menyayangi tanaman kepada teman-temannya ataupun kepada keluarga di rumah. Peningkatan kecerdasan naturalis dengan menggunakan metode bercocok tanam ini sebagai proses pembelajaran yang memberikan manfaat terhadap semua aspek perkembangan anak. Penggunaan metode bercocok membuat anak terlibat secara langsung dalam proses pembelajaran. Karena anak tidak hanya belajar di sekolah, tapi anak juga diajak langsung untuk mengamati kebun petani untuk melakukan pengamatan terhadap tumbuhan dan lingkungan perkebunan. Selain itu juga anak terlibat aktif dalam proses pembelajaran, karena anak mempunyai pengalaman langsung terhadap setiap materi yang dipelajari, sehingga kecerdasan naturalis anak dapat meningkat. Metode bercocok tanam dalam meningkatkan kecerdasan naturalis anak ini juga sebagi proses pembelajaran yang menyenangkan karena anak dapat mengeksplorasi diri dan anak juga bisa tahu proses dari mulai menanam tumbuhan, merawat tumbuhan hingga memanen hasil. Oleh karena itu dapat ditarik kesimpulan bahwa penggunaan metode bercocok ini dapat dijadikan media pembelajaran yang efektif dalam meningkatkan kecerdasan naturalis, khususnya dalam mengenali dan memahami secara mendetail mengenai flora (tumbuhan).

2. Peningkatan kecerdasan naturalis melalui metode bercocok tanam pada kelompok B di KB TK Asaloka Jakarta Barat mencapai standar keberhasilan 92\%, yaitu ada pada kategori berkembang sesuai harapan (BSH). Hal ini dapat dilihat dari hasil persentase kenaikan ratarata nilai siswa dalam satu kelas. Berdasarkan tindakan di setiap siklus penelitian tindakan kelas ini memperoleh peningkatan kecerdasan naturalis anak dari mulai tindakan pra siklus dengan perolehan rata-rata nilai 1,3 . Jika dipersentasekan sebesar $32 \%$, siklus 1 dengan perolehan rata-rata nilai 2,6. Jika dipersentasekan sebesar $62 \%$, dan siklus 2 dengan perolehan rat-rata nilai 3,7. Jika dipersentasekan sebesar 92\%. Hasil analisis menyatakan bahwa dari mulai pra siklus hingga siklus 2 mengalami perubahan dan peningkatan yang signifikan, hal ini dikarena setiap siswa khususnya siswa TK B di KB TK Asaloka Jakarta Barat sangat antusias dengan kegiatan bercocok tanam dan memiliki rasa ingin tahu yang besar dalam setiap proses pembelajaran. Sehingga siswa mampu memahami setiap penjelasan dan pembelajaran yang diberikan.

\section{DAFTAR PUSTAKA}

Armstrong, T. (2009). Multiple Intelligences in The Classroom. Virginia: ASCD Member Book.

Muspiroh , T. (2014). Pengembangan Kecerdasan Majemuk. Tangerang Selatan: Universitas Terbuka.

Suyadi. (2009). Anak yang Menakjubkan. Jogjakarta: Diva Press.

Yasbiati, Naturalis, R., \& Annisa, L. (2017). Upaya Meningkatkan Kecerdasan Naturalis melalui Kegiatan Bercocok Tanam di Bambim Al Abror Kecamatan Mangkubumi Kota Tasik Malaya. Jurnal Mahasiswa UPI.

Yaumi, M. \& Ibrahim N. (2013). Pembelajaran Berbasis Kecerdasan Jamak Mengindentifikasi dan Mengembangkan Multitalenta Anak. Jakarta: Kencana Prenadamedia Group. 
Yunisari, D., \& Amsal, A. F. (2016). Pengembangan Kecerdasan Naturalis Anak di Sentra Bahan Alam Pada Paud Terpadu Dharma Wanita Kota Jhanto Kabupaten Aceh Besar. Jurnal Ilmiah Mahasiswa Pendidikan Anak Usia Dini, 11-18.
Vol. 1, No. 1,

October 2019,

pp. $31-36$

e-ISSN:

2686-5009 